\title{
Behavior of Self-Compacting Concrete-Filled Steel Tube Columns with Inclined Stiffener Ribs under Axial Compression
}

\author{
W. Liang, ${ }^{a}$ J. F. Dong, ${ }^{a, 1}$ S. C. Yuan, ${ }^{b}$ and Q. Y. Wang ${ }^{\mathrm{b}}$ \\ a School of Architecture and Environment, Sichuan University, Chengdu, China \\ ${ }^{\mathrm{b}}$ Failure Mechanics and Engineering Disaster Prevention and Mitigation Key Laboratory of Sichuan \\ Province, Sichuan University, Chengdu, China \\ ${ }^{1}$ apiver@sohu.com
}

This study outlines the experimental investigation of the steel tube columns filled with selfcompacting concrete under axial compression. The effect of the stuffening arrangements and the concrete strength on the properties of the concrete-filled steel tube columns having stuffeners of different geometric dimensions has been investigated. The failure modes, ultimate loads, stuffness, ductility and strain response of the concrete-filled steel tube columns during the experiment have been analyzed. The results imply that the local buckling of the steel tubes can be delayed by the stuffeners. Moreover, the specimen with the four-sided stuffening arrangement possesses higher stuffness and better ductility as compared with the two-sided one. The test results also demonstrate that the proposed stffening schemes can improve the ultimate compressive capacity. The predicted ultimate loads have been compared using the existing codes, and the modified formula has been proposed. A good agreement between the theoretical and the experimental results is observed.

Keywords: concrete-filled steel tube, self-compacting concrete, stiffening, axial compression.

Introduction. Concrete-filled steel tube (CFST) structural elements are used worldwide as primary columns and beam-columns in high-rise buildings to resist the frame lateral load. They exhibit higher strength and stiffness values, good ductility, and etc $[1,2]$. The composite structure makes it possible to use the materials adequately and to strengthen the CFST columns [3]. To reduce in steel consumption and welding workload, the thin-walled steel tubes are widely used instead of the commercial steel tubes with the subsequent development and application of high-performance steel. However, local bucking easily occurs on the thin-walled concrete-filled steel tube due to its insufficient confinement, particularly when the square or rectangular cross sections are used $[4,5]$.

Many attempts have been made to investigate the enhancement as well as the performance of CFST using different stiffening methods [6-8]. They demonstrated their efficiency in delaying the local buckling of the steel tubes, and also their moderate effect on the ultimate compressive capacity. Furthermore, due to application of the thin-walled steel tubes, the steel tube strain decreases sharply after peak loads. However, the strengthening of CFST with tie bars or binding bars is not only an inconvenient method, but also makes the internal structure of the composite rather complex resulting in the concrete casting and curing quality damage. Also, the steel tube with longitudinal stiffeners is able to buckle locally near the upper end. This can be due to the fact that load is not perfectly applied to be evenly distributed across the cross-section at the ends of the stiffened CFST.

To improve the values of strength and ductility of the CFST columns, a new stiffening scheme is proposed. The steel tube with the inclined stiffener ribs at the top, the midships and the bottom has been developed to ensure free buckling. The self-compacting concrete (SCC) makes it possible to provide the thorough concrete flow to fill the gaps, and it requires no additional vibration for compaction in the strengthened CFST $[9,10]$. Due to excellent flow ability and easy workability, the stiffened specimens can be made easily and compacted well to ensure the concrete casting quality. Therefore, this paper presents two

(C) W. LIANG, J. F. DONG, S. C. YUAN, Q. Y. WANG, 2017 
types of SCC with different strength values to investigate the concrete strength effect on the mechanical properties of new CFST columns.

1. Experimental Procedure.

1.1. Material Properties. Two types of SCC were tested (Table 1). Slump flow and U-box tests were used to demonstrate the filling and segregation resistance ability for such mixtures. Slump flow testing with geometrical parameters of $600-750 \mathrm{~mm}$ and U-box filling with the height of more than $300 \mathrm{~mm}$ [11] together with the test results are presented in Table 2. It is evident that the results are consistent with the requirements of SCC use in the CFST columns.

$\mathrm{T}$ a

SCC Content (in $\mathrm{kg} / \mathrm{m}^{3}$ )

\begin{tabular}{|c|c|c|c|c|c|c|}
\hline Concrete code & Water & Cement & Fly ash & Gravel & Sand & SP \\
\hline C1 & 180 & 365 & 198 & 895 & 720 & 1.13 \\
C2 & 169 & 385 & 210 & 895 & 720 & 1.20 \\
\hline
\end{tabular}

$\mathrm{T}$ a $\mathrm{b} 1$ e 2

SCC Properties and Strength

\begin{tabular}{|c|c|c|c|c|}
\hline \multirow{2}{*}{$\begin{array}{l}\text { Concrete } \\
\text { code }\end{array}$} & \multicolumn{2}{|c|}{ Slump flow test } & \multirow{2}{*}{$\begin{array}{c}\text { U-box test } \\
H(\mathrm{~mm})\end{array}$} & \multirow{2}{*}{$\begin{array}{c}f_{c u} \\
(\mathrm{MPa})\end{array}$} \\
\hline & Diameter (mm) & $T_{500}(\mathrm{~s})$ & & \\
\hline $\mathrm{C} 1$ & 658 & 4.1 & 344 & 46.9 \\
\hline $\mathrm{C} 2$ & 620 & 3.4 & 323 & 63.2 \\
\hline
\end{tabular}

The concrete cubes $(150 \times 150 \times 150 \mathrm{~mm})$ were cured in the moist chamber with $20 \pm 2^{\circ} \mathrm{C}$. A rather high humidity of $95 \%$ was observed in the concrete compressive strength testing during 28 days. The concrete strength value was between 40 and $70 \mathrm{MPa}$ as expected, which is common for SCC used in engineering structures [12]. The strength values for such two types of concrete are also listed in Table 2.

The steel tubes used for the CFST columns are cold-formed tubes. The steel mechanical properties were determined complying with the Chinese Standard GB2975 [13], where the tensile strength is $390.0 \mathrm{MPa}$, the yield strength is $300.3 \mathrm{MPa}$, the elastic modulus is $195.4 \mathrm{GPa}$, and Poisson's ratio is 0.27 .

1.2. Test Specimens. The typical stiffeners with their parameters for each specimen are illustrated in Fig. 1 and Table 3, respectively. The two angle joints of every steel tube were welded, and each stiffener was welded with three welding spots. The parameters of $t_{s}$ and $w$ denote the stiffener thickness and width, $n$ denotes the number of the stiffened tube faces, and $a$ refers to the steel ratio.

The steel sheets with the thickness of $2.0 \mathrm{~mm}$ and of $1.8 \mathrm{~mm}$ were used in the specimens' construction. The width-to-thickness ratio of the square tubes was taken as 52 , and the total length of the specimens was $400 \mathrm{~mm}$. The test specimens were labeled with 'concrete type-stiffening scheme'. In order to determine the value of strength of the steel tubes, the bare steel tubes (series ' $\mathrm{C} 0$ ') were also tested (Table 3).

1.3. Test and Procedure. All the specimens were made and tested under axial compressive load. The overall axial displacement was measured by the two linear variable differential transducers (LVDTs) that are symmetrically attached. Six strain gauges were attached on the external surface of each CFST to measure the longitudinal and the transverse strains. Prior to testing, two steel plates with the thickness of $15 \mathrm{~mm}$ were placed 
W. Liang, J. F. Dong, S. C. Yuan, and Q. Y. Wang

$\mathrm{T}$ a b 1 e 3

Properties and Test Results

\begin{tabular}{|c|c|c|c|c|c|c|c|}
\hline Specimen & $\begin{array}{c}B \times t \times L \\
(\mathrm{~mm})\end{array}$ & $\begin{array}{c}t_{s} \\
(\mathrm{~mm})\end{array}$ & $n$ & $\begin{array}{c}W \\
(\mathrm{~mm})\end{array}$ & $\begin{array}{c}f_{c u} \\
(\mathrm{MPa})\end{array}$ & $\begin{array}{c}\alpha \\
(\%)\end{array}$ & $\begin{array}{c}N_{u e} \\
(\mathrm{kN})\end{array}$ \\
\hline C0-F2W10 & $104 \times 2 \times 400$ & 1.8 & 2 & 10 & - & - & 164.5 \\
C0-F2W20 & $104 \times 2 \times 400$ & 1.8 & 2 & 20 & - & - & 155.8 \\
C0-F4W10 & $104 \times 2 \times 400$ & 1.8 & 4 & 10 & - & - & 173.5 \\
C0-F4W20 & $104 \times 2 \times 400$ & 1.8 & 4 & 20 & - & - & 157.9 \\
\hline C1-F2W10 & $104 \times 2 \times 400$ & 1.8 & 2 & 10 & 46.9 & 8.45 & 913.0 \\
C1-F2W20 & $104 \times 2 \times 400$ & 1.8 & 2 & 20 & 46.9 & 8.75 & 877.9 \\
C1-F4W10 & $104 \times 2 \times 400$ & 1.8 & 4 & 10 & 46.9 & 8.75 & 958.7 \\
C1-F4W20 & $104 \times 2 \times 400$ & 1.8 & 4 & 20 & 46.9 & 9.34 & 931.7 \\
\hline C2-F2W10 & $104 \times 2 \times 400$ & 1.8 & 2 & 10 & 63.2 & 8.45 & 897.7 \\
C2-F2W20 & $104 \times 2 \times 400$ & 1.8 & 2 & 20 & 63.2 & 8.75 & 879.8 \\
C2-F4W10 & $104 \times 2 \times 400$ & 1.8 & 4 & 10 & 63.2 & 8.75 & 1037.0 \\
C2-F4W10 & $104 \times 2 \times 400$ & 1.8 & 4 & 20 & 63.2 & 9.34 & 908.2 \\
\hline
\end{tabular}

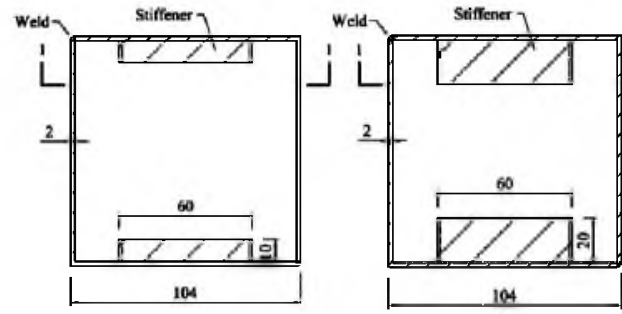

(a) $\mathrm{F} 2 \mathrm{~W} 10$ (b) $\mathrm{F} 2 \mathrm{~W} 20$

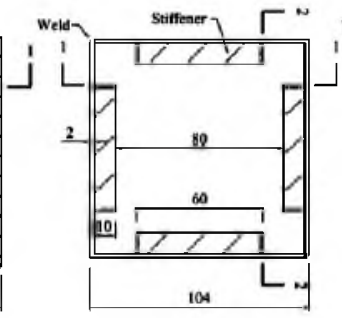

(c) F4W10

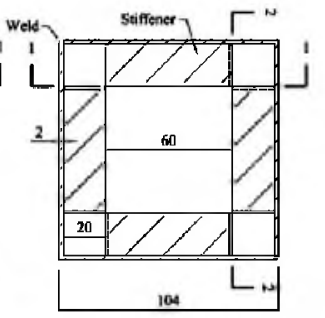

(d) F4W20

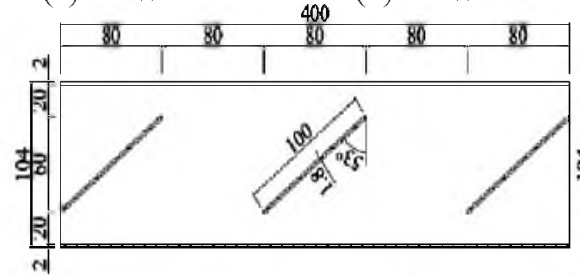

(e) Section 1

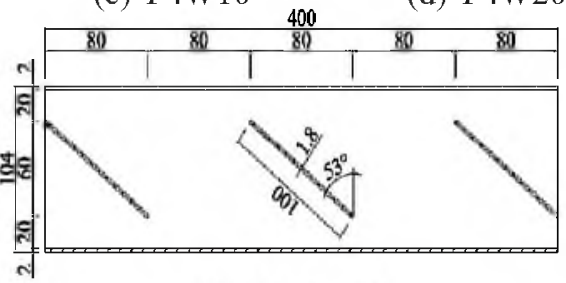

(f) Section 2

Fig. 1. Stiffening scheme for the specimens tested.

between the testing machine and the specimen ends to avoid the end effect. The strain and deformation data were recorded at each load increment of $10 \mathrm{kN}$.

2. Test Results and Discussion.

2.1. Failure Modes and Ultimate Load Carrying Capacity. The failure modes typical of the specimens are illustrated in Fig. 2. The local buckling for the bare steel tubes (series C0) was observed at both inner and outer surfaces of the steel tube. It was mainly visible between the two ends of stiffeners and the non-stiffened region, except for $\mathrm{C} 0$-F2W10. This is due to the presence of the $10 \mathrm{~mm}$ width stiffener rib that ensures the lower bending rigidity as compared with the $20 \mathrm{~mm}$ width one, and the integral rigidity of the specimen with the two-sided strengthening was lower in comparison with the four-sided strengthening one. For the C1-F2W20 and C1-F4W10 specimens, significant deformation was observed at the top angle due to stress concentration at the angle of pressure surfaces that were not polished properly. 


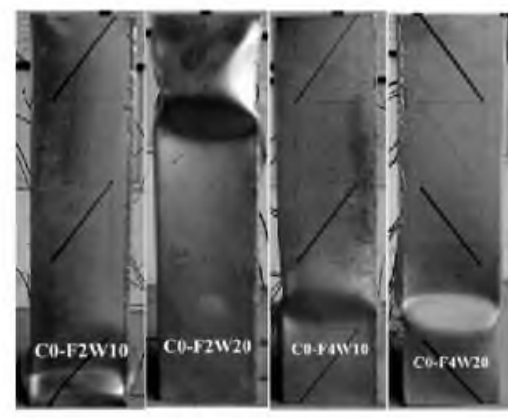

(a) $\mathrm{C} 0$ series

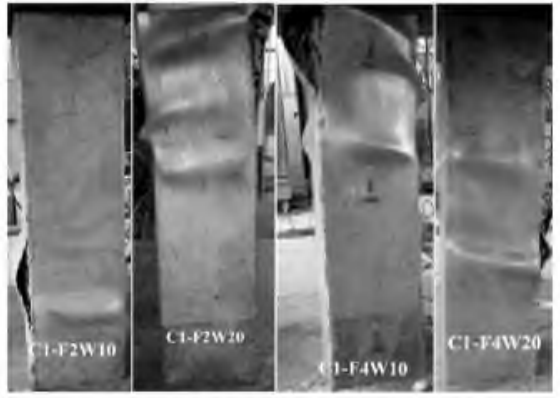

(b) $\mathrm{Cl}$ series

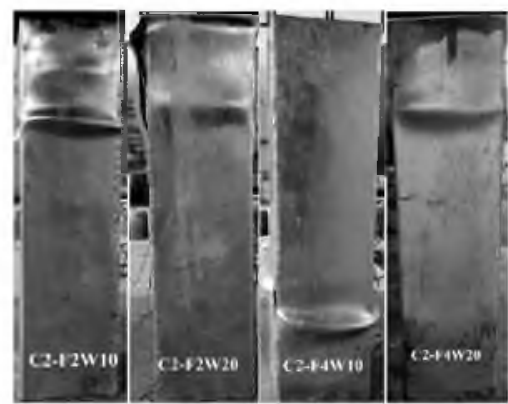

(c) $\mathrm{C} 2$ series

Fig. 2. Failure modes for the specimens.

The test results of the maximum loads $\left(N_{u e}\right)$ are shown in Table 3. It can be seen that the ultimate load carrying capacity of the bare steel tube specimens had no evident difference. However, for the steel tube filled with SCC concrete specimens, the ultimate load carrying capacity has considerably increased. Apparently, according to F2 and F4 types, the compressive capacities of the specimens with $10 \mathrm{~mm}$ width stiffening ribs were higher as compared with that ones of the specimens with $20 \mathrm{~mm}$ width stiffening ribs. This could be due to the fact that the hardened concrete was partitioned by stiffeners and, as a result, its structural integrity was affected. The integrity of concrete became worse with the larger stiffener width. Moreover, the columns of F4 type exhibit better compressive properties than that of type F2. However, there are some specimens with high concrete strength that causes the lower ultimate load carrying capacity. This may be explained by the early buckling at the outer surface of the steel tube and the cracks initiation as well as vertical propagation along the welding line, which imposes not much restriction on the concrete crushing during testing.

2.2. Load-Displacement Curve. The usual load-displacement curve can be generally characterized by three processes: elastic stage, elastic-plastic stage and post peak stage [14]. The $\mathrm{C} 0-\mathrm{F} 2 \mathrm{~W} 10$ and $\mathrm{C} 0-\mathrm{F} 2 \mathrm{~W} 20$ bare steel tubes with the two-sided stiffening columns are shown to have longer elastic-plastic stage in comparison with the C0-F4W10 and C0-F4W20 steel tubes with four-sided stiffening columns, as shown in Fig. 3a.

For $\mathrm{C} 1$ and $\mathrm{C} 2$ series specimens, the linear region was approximately developed up to the $70-80 \%$ of the peak load. The F2 and F4 series specimens showed the similar load versus displacement results, particularly at the elastic-plastic stage. For the C2-F2W10 specimens, the results were not evident, which might be explained by the specimen discreteness in the testing. The results also show that the width of stiffening ribs has no drastic effect on the CFST columns stiffness, and the internal rigidity is determined by the stiffening scheme. 


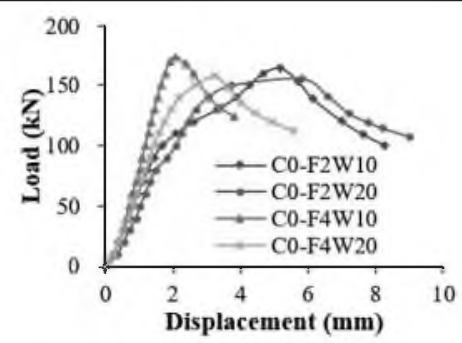

(a) $\mathrm{C} 0$ series

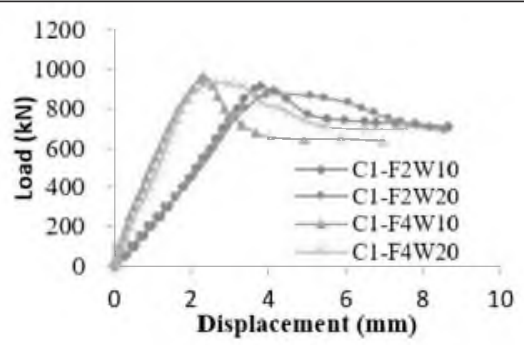

(b) $\mathrm{C} 1$ series

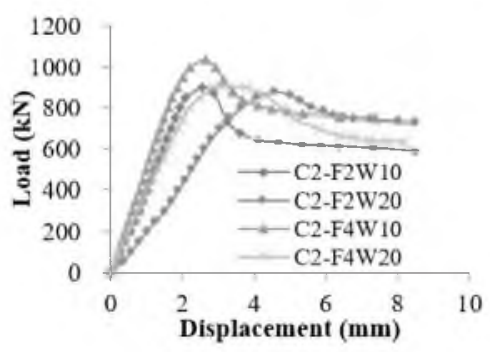

(c) $\mathrm{C} 2$ series

Fig. 3. Load-displacement curves of the specimens tested.

2.3. Strain Response. The strain response results are shown in Fig. 4. It can be found that the strains of $\mathrm{Cl}$ series with the two-sided stiffening scheme are much larger than the strains of $\mathrm{C} 2$ series (Fig. 4a and b). However, the results for the specimens with the four-sided stiffening scheme are quite different, as shown in Fig. $4 \mathrm{c}$ and $\mathrm{d}$. By comparing the load-strain curves of the maximum plastic deformation of the specimens with the two-sided stiffening scheme, the $\mathrm{C} 1$ series is much more serious than the $\mathrm{C} 2$ series. This is due to the concrete strength of $\mathrm{C} 1$ series which is lower than that of $\mathrm{C} 2$ series, which leads to earlier crushing in the $\mathrm{C} 1$ concrete.

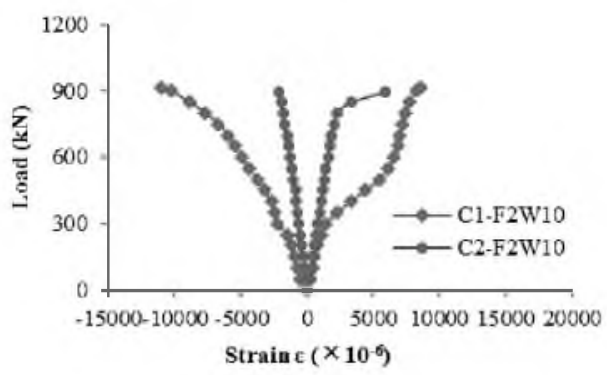

(a) F2W10

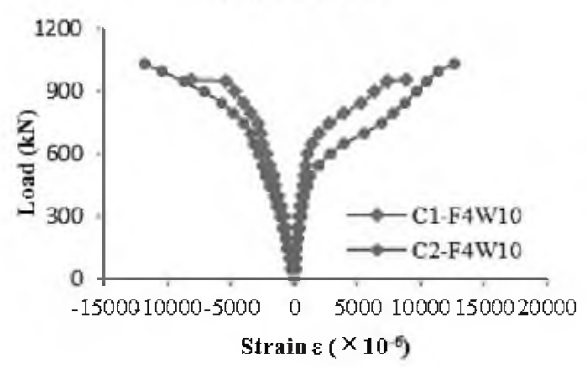

(c) F4W10

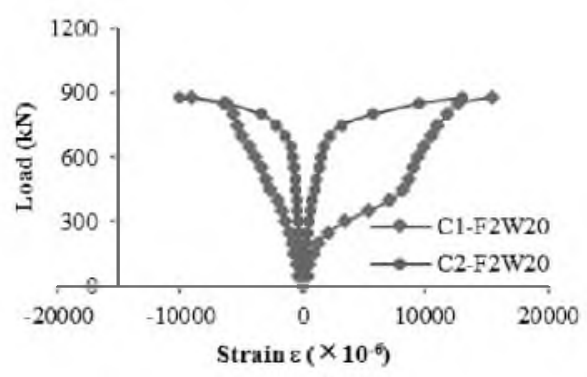

(b) F2W20

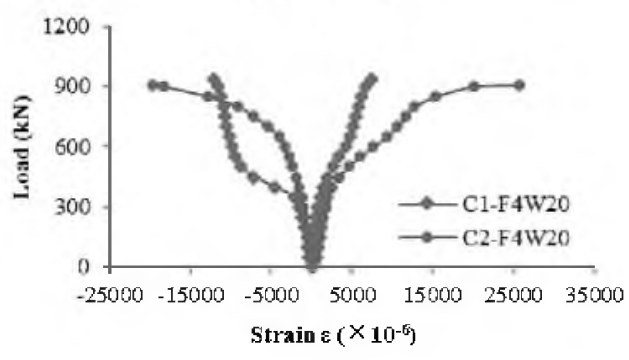

(d) F4W20

Fig. 4. Load-strain curves of series of $\mathrm{C} 1$ and $\mathrm{C} 2$ CFST columns. 
The four-sided stiffening specimens (C2 series) demonstrate higher ultimate deformation as compared with that of $\mathrm{C} 1$ specimens, which is explained by higher stiffness of the four-sided stiffening steel tube columns. During testing, the concrete crush for the specimens (C1 series) did not induce an outer surface steel deformation immediately, the concrete and steel tube could not be well combined. However, for the specimens (C2-F4), the concrete rupture and the local buckling of the steel tube were observed almost at the same time. Even for the specimens of $\mathrm{C} 2-\mathrm{F} 4$ series the elastic-plastic stage took place a bit earlier, which proved better ductility performance than that of the specimens (C1-F4 series).

2.4. Prediction of the Ultimate Load Carrying Capacity. A few design codes are taken to calculate the nominal compressive capacity of the unstiffened CFSTs, including ACI [15], BS5400 [16], EC4 [17]. The equations are expressed as follows:

$$
\begin{gathered}
N_{A C I}=A_{s} f_{y}+0.85 A_{c} f_{c}^{\prime}, \\
N_{B 55400}=A_{s} f_{y}+0.675 A_{c} f_{c u}, \\
N_{E C 4}=A_{s} f_{y}+A_{c} f_{c}^{\prime} .
\end{gathered}
$$

In the above formulas, $f_{c u}$ and $f_{c}^{\prime}=(0.79 \sim 0.81) f_{c u}$ are the cube and the cylinder strength values of concrete, respectively [18], while $f_{y}$ is the steel yield strength. For stiffened CFT columns in this paper, $A_{s} f_{y}$ is replaced with $A_{s, t} f_{y, t}+A_{s s s} f_{y, s}$ to consider the positive effect of the stiffeners. The area of stiffeners $A_{s, s}$ is estimated as follows:

$$
A_{s, s}=n \frac{t_{s} l_{s} w}{s},
$$

where $t_{s}, l_{s}$, and $w$ are the thickness, length and width of the stiffener, respectively, $s$ is the spacing distance between the stiffeners along the specimen axis direction, and $n$ is the number of the stiffened tube faces.

It can be seen from Table 4 that Eqs. (1)-(3) show much lower ultimate strength value of about $22 \sim 40 \%$. This should be due to the fact that the contribution of the interaction between the steel tube and the concrete is not taken into consideration in these equations. The composite action can be described using the confinement factor $(\xi)$ [19]:

$$
\xi=\frac{A_{s} f_{y}}{A_{c} f_{c k}}=\alpha \frac{f_{y}}{f_{c k}},
$$

where $A_{s}$ and $A_{c}$ are the areas of steel and concrete, $\alpha$ is the steel ratio, and $f_{c k}$ is the characteristic strength of the concrete equals to $0.67 f_{c u}$ for the normal strength concrete. For stiffened CFST columns, the ultimate capacity can be expressed as $[8,20]$ :

$$
N_{P}=A_{s c} f_{s c y}+A_{s, s} f_{y, s}
$$

where $A_{s c}$ is the sum of the cross-sectional zones of the steel tube and the concrete core, and $f_{s c y}$ is the nominal average strength of the composite structural element. In this paper, $f_{s c y}$ is taken as

$$
f_{s c y}^{s}=(175+285 k) f_{c k}
$$

where $k$ is the coefficient of axial compression strength for the stiffened CFT column, which considers the effects of confinement factor, stiffened scheme and effective concrete core: 


$$
k=\xi k_{n} k_{a}, \quad k_{n}=(n / 2)^{0.8}, \quad k_{a}=0.1 e^{a},
$$

where $a=A_{c o r} / A_{c}$ is the coefficient of the core concrete efficient area. The core concrete area $A_{c o r}$ is taken as the shadow region shown in Fig. 5.

$\mathrm{T}$ a b 1 e 4

Comparison of the Predicted Ultimate Strengths and Test Results

\begin{tabular}{|l|c|c|c|c|c|c|c|}
\hline Specimen & $\begin{array}{c}N_{u e} \\
(\mathrm{kN})\end{array}$ & $\frac{N_{A C I}}{N_{u e}}$ & $\frac{N_{B S 5400}}{N_{u e}}$ & $\frac{N_{E C 4}}{N_{u e}}$ & $\begin{array}{c}N_{P} \\
(\mathrm{kN})\end{array}$ & $\frac{N_{P}}{N_{u e}}$ & $D I$ \\
\hline C1-F2W10 & 913.0 & 0.63 & 0.62 & 0.69 & 776.9 & 0.85 & 1.37 \\
\hline C1-F2W20 & 877.9 & 0.66 & 0.66 & 0.72 & 757.1 & 0.86 & 1.91 \\
\hline C1-F4W10 & 958.7 & 0.60 & 0.60 & 0.66 & 877.0 & 0.91 & 1.44 \\
\hline C1-F4W20 & 931.7 & 0.64 & 0.63 & 0.70 & 838.8 & 0.90 & 2.14 \\
\hline C2-F2W10 & 897.7 & 0.76 & 0.75 & 0.84 & 979.8 & 1.09 & 1.47 \\
\hline C2-F2W20 & 879.8 & 0.78 & 0.78 & 0.87 & 960.1 & 1.09 & 1.78 \\
\hline C2-F4W10 & 1037.0 & 0.66 & 0.66 & 0.74 & 1079.9 & 1.04 & 1.67 \\
\hline C2-F4W20 & 908.2 & 0.77 & 0.77 & 0.85 & 1041.7 & 1.15 & 2.06 \\
\hline
\end{tabular}

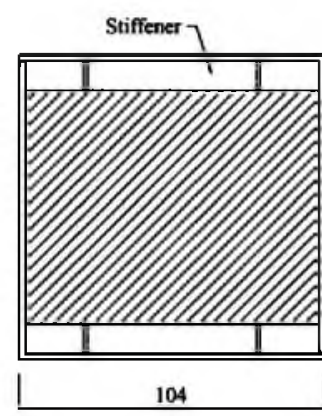

(a) F2W10

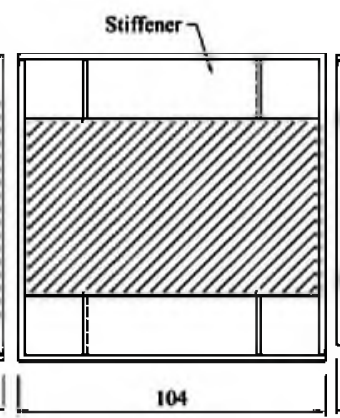

(b) F2W20

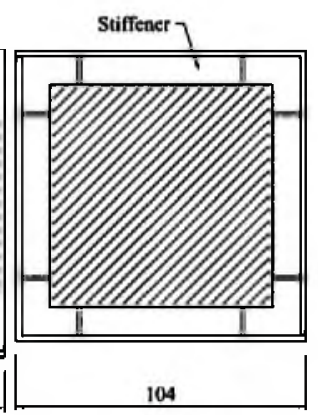

(c) F4W10

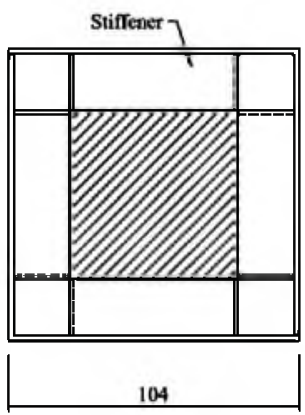

(d) F4W20

Fig. 5. Core concrete of the specimens tested.

As shown in Table 4, a profound estimate is obtained using modified Eq. (6), and the calculated results are consistent with the test values and analysis on the ultimate loads: $\mathrm{F} 2 \mathrm{~W} 20<\mathrm{F} 2 \mathrm{~W} 10<\mathrm{F} 4 \mathrm{~W} 20<\mathrm{F} 4 \mathrm{~W} 10$. Noteworthy is that the prediction values of $\mathrm{C} 2$ series from Eq. (6) are somewhat higher. This is due to the fact that the high strength of $\mathrm{C} 2$ concrete was not fully used before the specimen failure in the process of testing. Therefore, the test values are lower than the expected ones.

To determine the effect of stiffeners on the sectional ductility, the ductility index (DI) is given as follows [21]:

$$
D I=\frac{\varepsilon_{85 \%}}{\varepsilon_{y}},
$$

where $\varepsilon_{85 \%}$ is the nominal axial shortening $(\Delta / L)$, when there is the decrease to $85 \%$ of the ultimate load, $\varepsilon_{y}$ is equal to $\varepsilon_{75 \%} / 0.75$, and $\varepsilon_{75 \%}$ is the nominal axial shortening with $75 \%$ of the ultimate load. 
The results of $D I$ from Table 4 imply that the ductility indexes of $\mathrm{C} 1$ and $\mathrm{C} 2$ series increase from 1.37 to 2.14 and from 1.47 to 2.06 , respectively, with the corresponding steel ratio increase. Also, the stiffener schemes can have a sharp effect on the ductility value. For both series, the improvements of the DI of specimens with $20 \mathrm{~mm}$ width of stiffeners are much higher than that ones with $10 \mathrm{~mm}$ width of stiffeners. For $\mathrm{C} 1$ series, the increases of $D I$ for the F2W20 and F4W20 specimens are 39 and 56\%, respectively, as compared with F2W10. Besides, for C2 series, $D I$ is observed to be higher for F2W20 and F4W20, 21 and $40 \%$, respectively.

Conclusions. Twelve experimental tests of CFSTs subjected to axial load were performed. Four methods, including that one based on the increase of the width of stiffeners and the stiffener number on each tube face, were used with the aim to enhance the ductility and the compressive capacity of the CFST columns. The following conclusions can be drawn from the investigation:

1. The striking difference between the failure modes of the CFST column and the bare steel tube column under axial compression was revealed. It is noteworthy that the concrete can be in good harmony with the steel tube due to the stiffeners inside. The outer and inner buckling at the corresponding areas can be avoided using welding stiffeners.

2. Noteworthy is that the concrete strength has no obvious effect on the ultimate compressive capacity due to the fact that the welding steel tube could not provide sufficient strength to confine the inside concrete core. However, the investigation has led us to conclude that the four-sided stiffening columns exhibit higher compressive strength as compared with the two-sided stiffening ones. Moreover, the compressive strength of the CFST columns with $10 \mathrm{~mm}$ width stiffeners was higher in comparison with that one of the columns with $20 \mathrm{~mm}$ width stiffeners due to the larger area of the concrete core.

3. It is not hard to appreciate that the local buckling of the stiffening steel tubes with high strength concrete was effectively slowed down. The four-sided stiffening columns demonstrated much higher stiffness and better ductility as compared with the two-sided stiffening ones.

4. The findings imply that the effect of the composite on the stiffened steel tube and concrete is not considered using the existing design codes, which leads to the prediction that the ultimate loads are much lower in comparison with the ones obtained experimentally. The modified formula was proposed, and the calculated values were in a good agreement with the test results. However, the results are only preliminary. Further work needs to be performed to validate the described conclusions.

Acknowledgments. The authors would like to thank for the financial support provided by the National Natural Science Foundation of China (No. 51408382). The first author gratefully acknowledges the support given by the China Scholarship Council (CSC).

1. B. Young and E. Ellobody, "Experimental investigation of concrete-filled coldformed high strength stainless steel tube columns," J. Constr. Steel Res., 62, No. 5, 484-492 (2006).

2. J. F. Dong, Q. Y. Wang, and Z. W. Guan, "Material and structural response of steel tube confined recycled earthquake waste concrete subjected to axial compression," Mag. Concrete Res., 68, No. 6, 271-282 (2016).

3. F. X. Ding, Z. W. Yu, Y. Bai, and Y. Z. Gong, "Elasto-plastic analysis of circular concrete-filled steel tube stub columns," J. Constr. Steel Res., 67, No. 10, 1567-1577 (2011).

4. J. F. Dong, Q. Y. Wang, and Z. W. Guan, "Structural behavior of recycled aggregate concrete-filled steel tube columns strengthened by CFRP," Eng. Struct., 48, 532-542 (2013). 
5. L. H. Han, W. Li, and R. Bjorhovde, "Developments and advanced applications of concrete-filled steel tubular (CFST) structures: Members," J. Constr. Steel Res., 100, 211-228 (2014).

6. C. S. Huang, Y. K. Yeh, G. Y. Liu, et al., "Axial load behavior of stiffened concrete-filled steel columns," J. Struct. Eng., 128, No. 9, 1222-1230 (2002).

7. Y. L. Long and J. Cai, "Stress-strain relationship of concrete confined by rectangular steel tubes with binding bars," J. Constr. Steel Res., 88, 1-14 (2013).

8. Z. Tao, L. H. Han, and Z. B. Wang, "Experimental behavior of stiffened concretefilled thin-walled hollow steel structural (HSS) stub columns," J. Constr. Steel Res., 61, No. 7, 962-983 (2005).

9. H. Okamura and M. Ouchi, "Self-compacting concrete," J. Adv. Concr. Technol., 1, No. 1, 5-15 (2003).

10. N. Su, K. C. Hsu, and H. W. Chai, "A simple mix design method for self-compacting concrete," Cement Concrete Res., 31, 1799-1807 (2001).

11. M. C. S. Nepomuceno, L. A. Pereira-de-Oliveira, and S. M. R. Lopes, "Methodology for the mix design of self-compacting concrete using different mineral additions in binary blends of powders," Constr. Build. Mater., 64, 82-94 (2014).

12. H. Lu, X. L. Zhao, and L. H. Han, "Testing of self-consolidating concrete-filled double skin tubular stub columns exposed to fire," J. Constr. Steel Res., 66, Nos. 8-9, 1069-1080 (2010).

13. GB2975. Test Standard for Steel Material [in Chinese], Chinese Planning Press, Peking (1982).

14. X. Chang, L. Fu, H. B. Zhao, and Y. B. Zhang, "Behaviors of axially loaded circular concrete-filled steel tube (CFT) stub columns with notch in steel tubes," Thin Wall. Struct., 73, 273-280 (2013).

15. ACI 318-99. Building Code Requirements for Reinforced Concrete (ACI 318-99) and Commentary (ACI 318R-99), American Concrete Institute, USA (1999).

16. BS5400-5. Steel, Concrete and Composite Bridges, Code of Practice for the Design of Composite Bridges, British Standards Institution, London (2005).

17. Eurocode-4. Design of Composite Steel and Concrete Structures, Part 1-1: General Rules and Rules for Building, British Standard Institution, London (2004).

18. L. P. Ye, Concrete Structures [in Chinese], Tsinghua University Press, Beijing (2005).

19. L. H. Han, G. H. Yao, and Z. Tao, "Performance of concrete-filled thin-walled steel tubes under pure torsion," Thin Wall. Struct., 45, No. 1, 24-36 (2007).

20. DBJ1351. Technical Specification for Concrete-Filled Steel Tubular Structures [in Chinese], The Construction Department of Fujian Province, Fuzhou (2003).

21. Z. Tao, L. H. Han, and D. Y. Wang, "Experimental behavior of concrete-filled stiffened thin-walled steel tubular columns," Thin Wall. Struct., 45, No. 5, 517-527 (2007). 